Article

\title{
A Bus-Sectionalized Hybrid AC/DC Microgrid: Concept, Control Paradigm, and Implementation
}

\author{
Jing Li ${ }^{1,+}$, Hongda Cai ${ }^{1, *,+} \mathbb{D}$, Pengcheng Yang ${ }^{2}$ and Wei Wei ${ }^{2}$ \\ 1 Department of Information and Electrical Engineering, Zhejiang University City College, Hangzhou 310000, \\ China; lijing@zucc.edu.cn \\ 2 College of Electrical Engineering, Zhejiang University, Hangzhou 310000, China; ypc196@zju.edu.cn (P.Y.); \\ wwei@zju.edu.cn (W.W.) \\ * Correspondence: caihongda@zju.edu.cn \\ + These authors contributed equally to this work.
}

Citation: Li, J.; Cai, H.; Yang, P.; Wei, W. A Bus-Sectionalized Hybrid AC/DC Microgrid: Concept, Control Paradigm, and Implementation. Energies 2021, 14, 3508.

https://doi.org/ 10.3390/en14123508

Academic Editor: André Madureira

Received: 13 May 2021

Accepted: 9 June 2021

Published: 12 June 2021

Publisher's Note: MDPI stays neutral with regard to jurisdictional claims in published maps and institutional affiliations.

Copyright: (c) 2021 by the authors. Licensee MDPI, Basel, Switzerland. This article is an open access article distributed under the terms and conditions of the Creative Commons Attribution (CC BY) license (https:// creativecommons.org/licenses/by/ $4.0 /)$.

\begin{abstract}
In the last several years, the coordination control of hybrid AC/DC microgrids (HMGs) has been gaining increasingly more attention. However, most of these discussions are focused on single-bus HMGs whose AC or DC bus is not sectionalized by AC or DC breakers. Compared with these single-bus HMGs, the bus-sectionalized HMG has more flexible topologies, more diverse operation modes, and consequently higher service reliability. However, meanwhile, these benefits also bring challenges to the stable operation of bus-sectionalized HMGs, particularly for mode switching. Relying on the national HMG demonstrative project in Shaoxing, China, this paper makes efforts to present the hierarchical control paradigm of a typical bus-sectionalized HMG toward standardization. The test results demonstrate that the proposed system provides seamless switching and uninterrupted power supply without controller reconfiguration among different operation modes. The operational data are also brought forth and analyzed to provide significant and useful experiences for designing and developing similar HMGs in the future.
\end{abstract}

Keywords: hybrid AC/DC microgrid; bus section; hierarchical control; multimode operation; seamless mode switching

\section{Introduction}

Hybrid AC/DC microgrids (HMGs) are expected to be the key component of the future distribution networks [1], which play an important role in the integration of AC or DC distributed renewable resources, the flexible access of DC loads, as well as the highly reliable power supply. The AC and DC components (sources, loads, and storage units) are segregated and connected to respective subgrids primarily to reduced the number of power conversion stages, thus increasing the overall efficiency [2,3]. This hybrid AC/DC power architecture thus improves the reliability and power quality of the overall system [4].

In HMGs, the DC subgrid is tied to the AC bus via one or multiple bidirectional DC / AC interlinking converters [5]. Thus, the stable and highly reliable operation of a HMG relies greatly on the coordinated control of interlinking converters [6]. Loh et al. proposed a normalization scheme for proper power management between the AC subgrid and DC subgrid [7]. The presented control method can be extended to achieve global power sharing among all the power-generating devices. This scheme can also be extended to include energy storage with the interlinking converter [8]. However, the interlinking converter can only manage the power flow between AC and DC subgrids, and the approach is validated for only one interlinking converter between the AC and DC subgrid. Peyghami et al. proposed an autonomous power sharing approach for interlinking converters by introducing a superimposed frequency on the DC subgrid [9]. In this approach, the DC converters superimposed a small AC voltage signal on the DC voltage, where the frequency of the AC signal is proportional to the corresponding output power. Therefore, 
the converters are coordinated together with the superimposed frequency based on droop method. However, the approach only manages the power flow between the AC and DC subgrids, which does not provide the voltage support function.

Besides the power management function, the interlinking converter can also be utilized to support the DC or AC bus voltage. Lu et al. proposed a three-level hierarchical control system. In the primary control level, the conventional DC-droop concept is adopted to support the DC bus voltage [10]. Wang et al. suggested a nonlinear disturbance observer (NDO)-based DC bus voltage control, which is developed to suppress the transient fluctuations of the DC bus voltage and improve the power quality in the HMG system [11]. However, both of the schemes in $[10,11]$ do not include the mode transition algorithms, and thus the operation mode of the interlinking converters are fixed.

There exist attempts to achieve multifunctional operation of the interlinking converter, including, but not limited to, power management, AC or DC voltage support. Liu et al. proposed a coordination control algorithm for stable system operation under grid-tied and autonomous mode [12]. The main AC/DC converter regulates the DC bus voltage in gridtied mode and maintains the AC bus voltage and frequency in the autonomous mode. Thus, the control configuration of the main AC/DC converter and the energy storage system need to be switched and reconfigured when the operation mode of the HMG changes. What's more, this depends heavily upon the essential islanding detecting methods and proper mode transition algorithms. Wang et al. put forward a uniform control strategy which unifies different control structures for multifunctional operation. With the unified control structure, various triggering mechanisms for the interlinking converter mode transition are omitted in response to the relevant scenario changes [13]. However, the utilization of the proportion integration (PI) controller in the voltage regulation loop restricts the extension of the method in the parallel operation scenario. Yang et al. proposed a decentralized bidirectional voltage supporting control strategy for interlinking converters [14]. An AC phase angle versus DC voltage inverse droop control with virtual impedance is designed to support both AC and DC voltages. However, the proposed control scheme can only achieve seamless mode transition in a passive way. The authors of [15] present a new structure of hybrid coupled interlinking converter (HCIC) as well as a new droop control method. A fast harmonic control is given to improve the filtering characteristics. HCIC for hybrid AC/LVDC microgrids has the ability of good power flow control and power quality compensation. However, the special structure restricts the population of the converter.

As for the coordination control of a HMG, Espina et al. proposed a consensus-based secondary control strategy for HMG [16]. The proposed control scheme improves the power-sharing accuracy and secondary control restoration of the variables in both AC and DC sides. Moreover, the proposed methodology avoids the circulating currents among interlinking converters. The work in [17] presents a GPS-based decentralized control strategy for HMG. In contrast with the existing control approaches, the proposed method does not require frequency or power calculations but directly uses voltage and current measurements because of the proposed per-unit method. Thus, the delay associated with the feedback signals is minimized. Biglarahmadi et al. used nonlinear exponential control and distributed secondary control schemes to properly control the HMG and form an integrated nonlinear hierarchical control and management for HMG [18] that achieves superiority over conventional controllers. However, the nonlinear control strategies need accurate system models for control design and analysis. Besides, the multimode operation and seamless mode transition schemes are not covered in the above literatures.

A variety of research works have been performed on the seamless operation mode switching in DC and AC microgrids [19]. However, so far, few efforts have been made on the seamless mode switching in hybrid AC/DC microgrids. Minho et al. proposed a control scheme for autonomous and seamless mode switching of bidirectional DC-DC converters in a DC microgrid [20]. To achieve seamless mode switching of the DC microgrid, the storage needs to take charge of the DC bus voltage in both grid-connected and islanded mode. However, the SOC restriction of the battery and power limit of the battery converter 
may lower the algorithm's practicability. Guannan et al. suggested a unified control scheme based on the disturbance observer [21]. The algorithm only focuses on seamless transition of inverter-interfaced distributed generation in the AC scenario. Vasilis et al. proposed a novel islanding detection method to ensure fast detection of the islanding condition of DC microgrids, thereby achieving a seamless transition between interconnected and islanded operation [22]. However, the islanding detection method needs the insertion of a controllable load which increases the system complexity.

Commonly, the AC bus and the DC bus take the single bus configurations as they are more cost-efficient, easier to realize, and simpler to control. However, on the other hand, the single-bus configuration reduces the reliability of the system, which also reduces the security of important devices and sensitive consumers. For example, a fault that occurs at any point of the system may result in a power service disruption of the entire system, and the fault may even transmit along the whole HMG. Therefore, there is an increasing demand to make the HMG bus-sectionalized, both for its AC bus and DC bus.

A bus-sectionalized hybrid AC/DC microgrid (BSHMG) has been developed in Shaoxing, Zhejiang Province, China, to solve the drawbacks of conventional single bus configurations. As the sectionalized bus configuration is adopted, the BSHMG has more flexible operation modes rather than grid-connected mode and islanded mode of those of single bus configuration. Thus, the multimode operation and seamless mode transition makes the coordinated control strategy of a BSHMG more complicated.

A coordinated hierarchical control fashion is proposed to achieve the stable multimode operation and seamless mode transition in this BSHMG. The proposed control paradigm makes efforts in its universality and generality, which is also an attempt to standardized transplantation and popularization. The standardization features of the proposed hierarchical control paradigm are summarized below.

1. By specialized control design arrangements, it is not necessary to switch the control scheme of each component in the BSHMG in response to different operation modes.

2. Based on the role of each component in the BSHMG, including DC voltage sources, AC voltage sources, dispatchable distributed generators, and PQ controlled converters, the function-based modularization design principle is adopted to make the control scheme extendable, especially for the extension of devices operating in parallel.

3. The introduced device state signal in the supervisory algorithm enables the communication fault ride-through capability, and the impact from the communication failures can thus be mitigated.

The proposed standardization-oriented hierarchical control paradigm is practically applied to the demonstrative project of BSHMG in Shaoxing, Zhejiang Province, China, and the the results of operation tests of the BSHMG are illustrated.

The rest of this paper is organized as follows. In Section 2, the system configuration and its four different operation modes of the introduced bus-sectionalized HMG are presented. Section 3 elaborates upon the adopted standardization-oriented hierarchical control strategy, including the coordination droop scheme for the primary control, the multimode operation, and seamless mode switching algorithm for the secondary control. Finally, the design and implementation of the demonstrative BSHMG are introduced. The test results in the demonstrative BSHMG are illustrated in Section 4 . Section 5 concludes the paper.

\section{Bus-Sectionalized AC/DC Microgrid}

\subsection{System Configuration}

The conceptual hybrid system configuration of a BSHMG is shown in Figure $1 \mathrm{a}$. As shown, the AC bus is sectionalized by the AC breaker KG1 into two subsections: 1\# AC bus and 2\# AC bus. Similarly, the DC bus is sectionalized by the DC breaker DCBr into two subsections: 1\# DC bus and 2\# DC bus. The AC bus is connected to the local utility, and the DC bus is connected to the AC bus through a power electronic transformer (PET) and bidirectional interlinking DC/ AC converters, which are called the power flow controllers 
(PFC) in this paper. The battery storage is connected to 2\# DC bus for higher reliability and efficiency. There exists four subgrids in the BSHMG: two AC subgrids and two DC ones. All the subgrids are integrated with distributed renewable energy sources and connected with local loads. Compared with the conventional single-bus HMG, the operation modes of the BSHMG are more flexible and complex because of the coexistence of subsections of the AC and DC bus. If the coordinated control is not well realized, the stable and efficient operation of the BSHMG will be influenced. Therefore, the proper coordinated control for the whole system is the key challenge for taking the advantages of the BSHMG, especially in multimode operation and seamless mode switching.

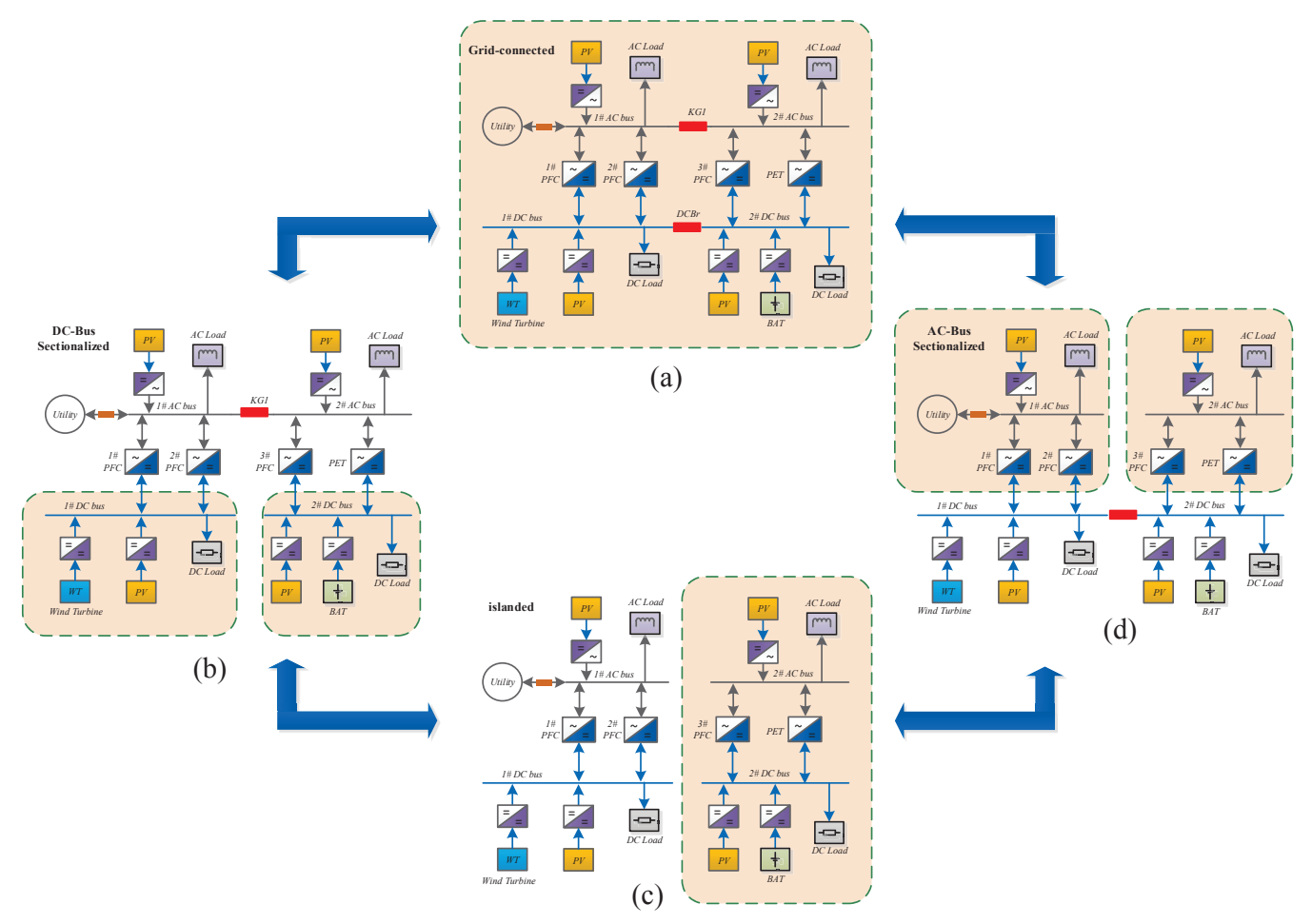

Figure 1. Four typical operation modes of the bus-sectionalized hybrid AC/DC microgrid (BSHMG). (a) Grid-connected mode; (b) DC-bus sectionalized mode; (c) Islanded mode; (d) AC-bus sectionalized mode.

\subsection{Multimode Operation}

Usually, for a conventional single-bus HMG, the only two operating modes are the grid-connected mode and the islanded mode as the only controllable breaker is the point of common coupling (PCC) which interlinks the HMG to the common utility. When a fault occurs, the entire damaged bus must be cut off in the single-bus HMG, while only the damaged section needs to be cut off for the remaining section to preserve the power generation and supply in a BSHMG.

In order to ensure uninterrupted power generation/supply in the other areas when a fault or scheduled/planned maintenance happens in the utility or one/some subgrids, the BSHMG is designed to operate in the following four modes: grid-connected, AC-bus sectionalized, DC-bus sectionalized, and islanded mode, as shown in Figure 1.

\subsubsection{Grid-Connected Mode}

In the grid-connected mode, the entire BSHMG is connected to utility. Both the AC breaker KG1 and DC breaker DCBr are in the closed position. From the view of supplydemand balance, the surplus power generated by the distributed sources is injected into the utility and insufficient power in turn is supplemented by the distribution network. 


\subsubsection{AC-Bus Sectionalized Mode}

When the AC bus has a fault or scheduled maintenance occurs, the AC breaker needs to be in the open position to isolate the fault/maintenance area. In this mode, the AC bus of the BSHMG is sectionalized into two subsections: $1 \# \mathrm{AC}$ bus and 2\# AC bus, while the DC breaker is still in the closed position.

\subsubsection{DC-Bus Sectionalized Mode}

When the DC bus has a fault or a scheduled maintenance occurs, the DC breaker needs to be in the open position to isolate the fault/maintenance area. In this mode, the DC bus of the BSHMG is sectionalized into two subsections: 1\#DC bus and 2\#DC bus, while the AC breaker is still in the closed position.

\subsubsection{Islanded Mode}

If the $\mathrm{DC}$ breaker is opened from the AC-bus sectionalized mode, or the AC breaker is opened from the DC-bus sectionalized mode, the BSHMG is switched to the islanded mode. In this mode, the 2\# AC bus is still connected with the 2\# DC bus through the 3\# PFC and the PET.

Note that both the AC and DC breaker can be cut off passively or actively; wherever the fault occurs in the BSHMG, the normal power generation and supply in areas that are isolated from the fault point may still be ensured.

\section{Hierarchical Control of Bus-Sectionalized Hybrid AC/DC Microgrid}

In the MG control hierarchies, the key points differentiating each control level are the control targets, response time, and communication requirement [23]. Primary control maintains the voltage/frequency to stabilize the system and provides immediate response to the system disturbance, while the secondary control is for voltage/frequency restoration, accurate power sharing, multimode operation, and seamless mode switching.

Standardization in the coordination control requires the control mechanism to be designed so that the key equipments' control scheme is compatible with both control layers. Note that it is preferable to use the same control configuration for all the different operation modes for the key equipments. Here, the key equipment indicates the voltage or frequency supporting devices; as for this BSHMG, they are PFCs and the battery storage. In order to achieve the standardization objective, a two-level hierarchical control paradigm with following features is designed:

1. The primary control level supports the DC-bus voltage regulation as well as the AC-bus voltage and frequency regulation.

2. The secondary control level restores the DC voltage and AC voltage and frequency to their reference values. Proper power flow sharing schemes are also achieved among PFCs, the PET, and the battery storage.

3. Seamless active or passive switching among the different operation modes are achieved through some active control strategies by the secondary control.

4. The PFCs, PET, and the battery storage are not necessary to change their primary control configurations in different operation modes.

\subsection{Primary Control}

For the studied BSHMG, the primary control is carried out by PFCs and the battery storage. The widely used droop control strategy (both for AC and DC sides) is adopted, which is also the fundamental (inner control loop in the control viewpoint) control for the secondary control layer. The dynamics of the primary control of all the devices in the BSHMG are elaborated as follows.

\subsubsection{1\# PFC and 2 \# PFC}

The key function of 1 \# PFC and 2 \# PFC is to maintain the DC-bus voltage while achieving power sharing between each other. On this point, the $V$-I type droop control on 
the DC side is selected to be their primary control strategy. The equation of the $V$-I type droop control is given by

$$
v_{D C}^{r e f}=V_{D C}^{*}+m \cdot\left(I_{0}-i_{D C}\right),
$$

where $v_{D C}^{r e f}$ is the reference voltage for the inner loop, $\mathrm{m}$ is the droop coefficients, $V_{D C}^{*}$ is the rated DC bus voltage, $I_{0}$ is the rated current of the PFC, and $i_{D C}$ is the DC output current. The adjustment of the rated voltage $V_{D C}^{*}$ can change the DC voltage output of the PFC, which is utilized to achieve DC bus voltage restoration. The adjustment of the rated current $I_{0}$ can change the current output and realize the accurate power sharing, while the adjustment of the droop coefficient can change the power sharing ratio.

\subsubsection{3\# PFC}

The main function of 3\# PFC is to support the AC voltage and frequency if $2 \#$ AC bus is disconnected from $1 \# \mathrm{AC}$ bus. Accordingly, the AC droop control method is set to be the primary control strategy of 3\# PFC. The control law for AC droop control method can be expressed as

$$
\begin{gathered}
f^{r e f}=f^{*}+r \cdot\left(P^{*}-P\right), \\
V_{A C}^{r e f}=V_{A C}^{*}+n \cdot\left(Q^{*}-Q\right),
\end{gathered}
$$

where $f^{r e f}$ and $V_{A C}^{r e f}$ are the reference values for the inner loops; $r$ and $n$ are the droop coefficients; $f^{*}$ and $V_{A C}^{*}$ are the rated frequency and voltage of the $\mathrm{AC}$ bus, respectively; and $P^{*}, Q^{*}, P$, and $Q$ are the rated active power, rated reactive power, actual active power, and actual reactive power, respectively. The adjustment of $f^{*}$ and $V_{A C}^{*}$ can achieve AC voltage and frequency restoration, while the adjustment of $P^{*}$ and $Q^{*}$ is utilized to realize accurate power sharing.

\subsubsection{PET}

Generally, the PET can be controlled as the same as 3\# PFC, while in this paper, the PET is controlled as a PQ source to show the universality of the proposed strategy. As a controlled PQ source, the adjustment of its $P$ and $Q$ references is mainly to realize the accurate power sharing between itself and other PFCs in parallel.

\subsubsection{Battery Storage}

The battery storage is connected to the 2\# DC bus and needs to provide DC voltage support and maintain the power balance when the $2 \#$ DC bus is disconnected from the $1 \#$ DC bus by the DC breaker. The primary control strategy for the battery storage is the DC $V$-I type droop control, which is as the same as that for 1\# PFC and 2\# PFC in the outer droop loop. Specifically, the adjustment of battery's output current can realize the constant power charging/discharging control, consequently to achieve the state of charge (SOC) control of the battery.

\subsubsection{PV Sources}

The distributed PV sources are the dominating renewable resource generators in the BSHMG. The dispatching of PV generation plays a key part in the power balance maintenance in the islanded or bus-sectionalized operation modes. Thus, the PV sources work in the power dispatching mode, and if the power command is higher than the maximum available power generation of the PV source, the PV source works in the MPPT mode; otherwise, if the the power command is lower than the maximum power generation of the PV source, it backs off its power generation to track the power references.

The coordination droop control strategies are summarized in Table 1 for clearer illustration. The devices that support the DC/AC voltage/frequency are called network supporting devices. 1\# PFC and 2\# PFC are the network supporting devices for the 1 \# DC bus and the battery storage is the network-supporting device for 2 \# DC bus, respectively, and $3 \#$ PFC is the network supporting device for 2 \# AC bus. Note that even though the 
battery storage is arranged as being connected to 2\# DC bus in the proposed BSHMG, in another configuration, it can be arranged to anywhere where there is sensitive load requiring connection to.

Table 1. Coordination Droop Control Strategy for Key Equipments of the BSHMG.

\begin{tabular}{|c|c|c|c|}
\hline Device & Control Method & Adjustable Parameter & Function \\
\hline $\begin{array}{l}\text { 1\# PFC } \\
\text { 2\# PFC }\end{array}$ & DC $V$-I droop & $\begin{array}{l}\text { DC rated voltage } \\
\text { DC rated current } \\
\text { Droop Coefficient }\end{array}$ & $\begin{array}{l}\text { DC-bus voltage restoration } \\
\text { accurate current sharing } \\
\text { power sharing ratio setting }\end{array}$ \\
\hline 3\# PFC & $\begin{array}{l}\text { AC } P-f \text { droop } \\
\text { AC } Q-V \text { droop }\end{array}$ & $\begin{array}{c}\text { AC rated frequency } \\
\text { AC rated acitve power } \\
\text { AC rated voltage } \\
\text { AC rated reactive power }\end{array}$ & $\begin{array}{l}\text { AC frequency restoration } \\
\text { active power sharing } \\
\text { AC voltage restoration } \\
\text { Reactive power sharing }\end{array}$ \\
\hline PET & PQ control & $\begin{array}{l}\text { P command } \\
\text { Q command }\end{array}$ & $\begin{array}{l}\text { active power sharing } \\
\text { Reactive power sharing }\end{array}$ \\
\hline Battery Storage & DC $V$-I droop & $\begin{array}{l}\text { DC rated voltage } \\
\text { DC rated current } \\
\text { Droop Coefficient }\end{array}$ & $\begin{array}{l}\text { DC-bus voltage restoration } \\
\text { accurate current sharing } \\
\text { power sharing ratio setting }\end{array}$ \\
\hline PV Source & Power Dispatching & $\begin{array}{c}\text { MPPT } \\
\text { Power dispatching }\end{array}$ & $\begin{array}{l}\text { Maximum power point tracking } \\
\text { power generation control }\end{array}$ \\
\hline
\end{tabular}

\subsection{Secondary Control}

A secondary control is needed so as to compensate for the frequency and DC/AC voltage amplitude deviations caused by the droop control method, as well as ensure the seamless mode switching among different operation modes, no matter whether the switching is performed passively or actively.

\subsubsection{Basic Control Principle}

The basic control framework of the proposed secondary control strategy is simplified and depicted in Figure 2. The secondary control strategy operates the BSHMG by adjusting $\delta v d c, \delta v i, \delta P, \delta f$, and $\delta v_{a c}$.

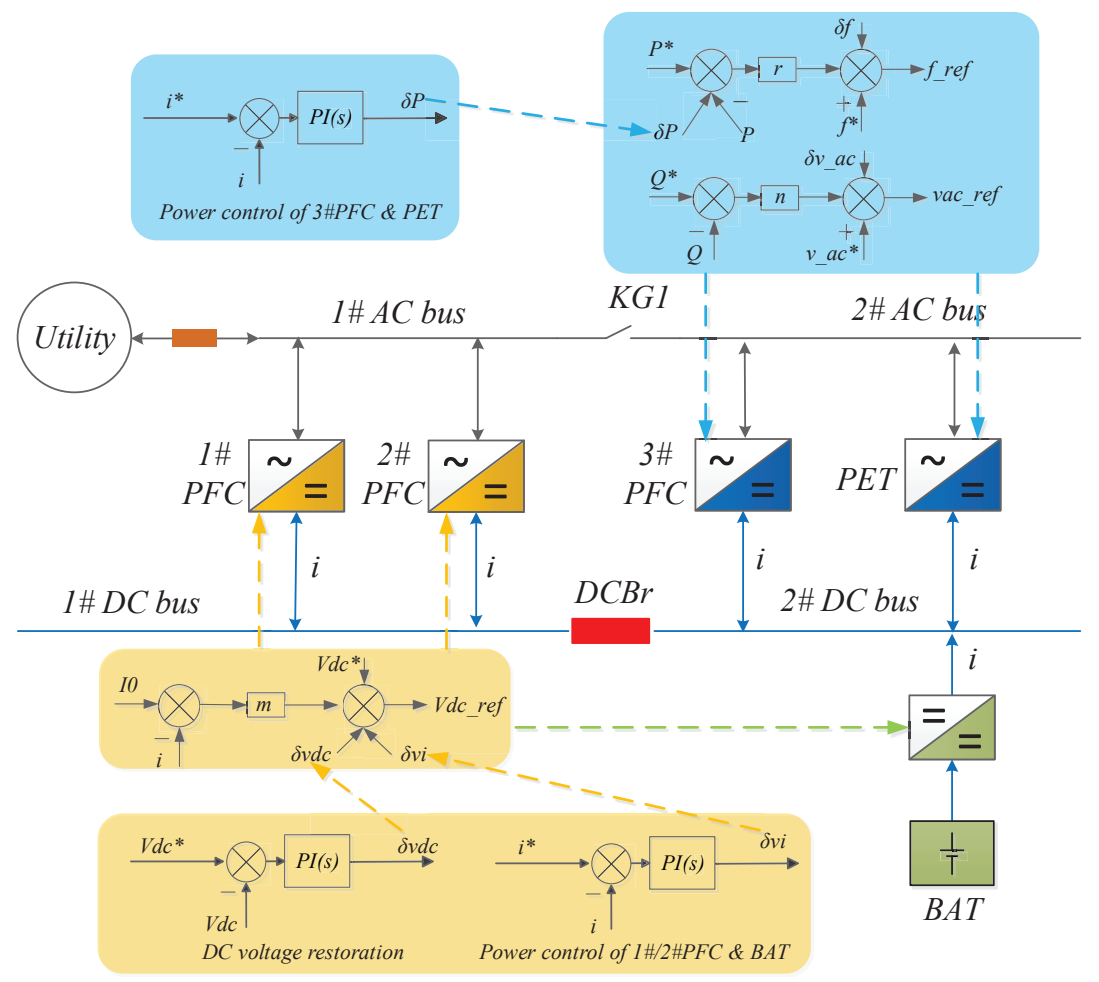

Figure 2. The basic control framework for the BSHMG. 


\section{(1) Power Flow Adjusting}

With the proposed secondary control, coordinated multimode operation and seamless mode switching are achieved by adjusting the $i^{*}$ reference of each converter without changing their inner loops, which can obviously make the system more reliable and scalable with less complexity.

As for voltage-support equipments, such as 1\# PFC, 2\# PFC, and the storage battery, by measuring the current (or the power), they can be compared with the desired positive or negative current (or the power), which depends on the desired current direction. The secondary current controller can be expressed as

$$
\delta v_{i}=k_{p}^{\prime}\left(i^{*}-i\right)+k_{i}^{\prime} \int\left(i^{*}-i\right) d t,
$$

where $k_{p}^{\prime}$ and $k_{I}^{\prime}$ are the control parameters. The term $i^{*}$ is the current reference value, which can be the average current of all the parallel devices who participate in the power sharing, or merely the current command for a special task, such as the battery SOC control or the seamless operation mode transition control. The term $i$ is the locally measured output current of the converter. As for the PQ-controlled equipments, such as $3 \#$ PFC (the $P-f / Q-V$ droop control can be regarded as PQ mode control when they are gridconnected) and the PET in this BSHMG, a modification of (4) is made to get the adjustment value for $\mathrm{P}$ command, which can be expressed as

$$
\delta P=k_{p}^{\prime}\left(i^{*}-i\right)+k_{i}^{\prime} \int\left(i^{*}-i\right) d t,
$$

Note that depending on the sign of $i^{*}$, the power flow can be imported to the DC bus $\left(i^{*}>0\right)$ or export from the DC bus $\left(i^{*}<0\right)$.

\section{(2) AC Bus Regulating}

For the AC side, the frequency and voltage amplitude levels in the 2\# AC bus, $f_{2 \# A C}$ and $v_{2 \# A C}$, are sensed and compared with references $f^{*}$ and $V_{A C}^{*}$; the errors are processed through the proportional-integral (PI) controllers, $\delta f$ and $\delta v_{A C}$, and are fed into the 3\# PFC to restore the output voltage amplitude and its frequency. The frequency and voltage amplitude restoration controllers in the secondary control can be obtained as follows:

$$
\begin{gathered}
\delta f=k_{p f}\left(f^{*}-f_{2 \# A C}\right)+k_{i f} \int\left(f^{*}-f_{2 \# A C}\right) d t, \\
\delta v_{A C}=k_{p v_{-} a c}\left(V_{A C}^{*}-v_{2 \# A C}\right)+k_{i v_{a} a c} \int\left(V_{A C}^{*}-v_{2 \# A C}\right) d t,
\end{gathered}
$$

where $k_{p f}, k_{i f}, k_{p v_{-} a c}$, and $k_{i v \_a c}$ are the control parameters of the frequency and voltage amplitude restoration controllers. The primary control is only based on the local measurements, while the secondary control needs a centralized controller to be implemented. The frequency and village amplitude adjustment values generated by (6) and (7) are fed into (2) and (3), the primary controller, to restore the deviations produced by the droop control.

(3) DC Bus Regulating

For the DC side, to solve the problem of the voltage deviation caused by (1), the secondary control is expressed as follows:

$$
\delta v_{D C}=k_{p v_{-} d c}\left(V_{D C}^{*}-v_{D C}\right)+k_{i v_{-} d c} \int\left(V_{D C}^{*}-v_{D C}\right) d t,
$$


where $k_{p v \_d c}$ and $k_{i v \_d c}$ are the proportional and integral gains of the controller, respectively. The $\delta v_{D C}$ command is sent to every DC voltage source, e.g., $1 \#$ PFC, 2\# PFC, and the battery storage. Finally, (1) becomes

$$
v_{D C}^{r e f}=V_{D C}^{*}+\delta v_{D C}+m \cdot\left(I_{0}-i_{D C}\right) .
$$

\section{(4) PV Power Control}

In case of certain PFC failures, too much PV power may overload the still-functioning equipments. Thus, the PV power needs to be dispatched to protect them. There are three significant items that need to be protected: the power limit of the PFC, the power limit of the battery's bidirectional DC/DC converter, and the battery's SOC. For any of the items to be protected, the PV dispatching equation is defined as

$$
P_{\text {pvcmd_y }}=P_{\text {pvmax }} \cdot\left(y_{\text {limit }}-y\right) /\left(y_{\text {limit }}-y_{\text {startup }}\right),
$$

where $P_{\text {pvcmd_y }}$ and $P_{\text {pvmax }}$ are the PV power dispatching command from the corresponding equipment $y$ and the maximum PV power, respectively. In (10), parameter $y$ and $y_{\text {limit }}$ represent the measurement and limit value of the item to be protected, respectively, which can be the power flow the PFC, the power flow of the bidirectional DC/DC converter of the battery, and the SOC. $y_{\text {startup }}$ is the start point at which the PV output power need to be limited.

Specifically for a PV source, the power dispatching command is given as

$$
P_{\text {pvcmd }}=\min \left(P_{\text {pvcmd_pfc1 }}, P_{\text {pvcmd_pfc2 }}, . .\right),
$$

where $P_{\text {pvcmd_y1 }}, P_{\text {pvcmd_y } 2}$ is the PV dispatching command from the corresponding equipment to be protected. Note that for a certain PV source, not all the equipments' dispatching commands are taken into (11) to calculate the PV dispatching power command, only the dispatching commands from the equipments that require to be protected by the this certain PV source are considered.

The specific control actions for every operation mode in the secondary control are given as follows:

\subsubsection{Multimode Operation}

\section{(1) Grid-connected Mode}

In grid-connected mode, except for voltage/frequency regulation, we need all the PFCs and the PET to share their power flow accurately. Particularly, the battery needs to be controlled in floating mode. The detailed control algorithm for grid-connected mode is elaborated as follows:

- Use (8) to regulate $\delta v_{D C}$ for $1 \#$ PFC and $2 \#$ PFC to restore the DC bus voltage. Calculate the average current $\left(i_{12}^{*}\right)$ of $i_{1}$ (for 1\# PFC) and $i_{2}$ (for 2\# PFC) and use it as the current reference $i^{*}$ in (4) to share their output power. To ensure the secondary algorithm is compatible with the failure of certain equipments, the fault state ( 1 for normal and 0 for fault) of every converter is collected by the secondary controller and added into the calculation of current references, which is given as

$$
i_{12}^{*}=\left(i_{1} \cdot s_{1}+i_{2} \cdot s_{2}\right) /\left(s_{1}+s_{2}\right),
$$

where $s_{1}$ and $s_{2}$ are the device states of 1\# PFC and 2\# PFC, respectively. Hereafter, the subscript of the term $s$ indicates the state of device $i$, which can be 1,2, or 3 for the PFCs or just the device names. 
- $\quad$ Calculate the weighted average current of $i_{1}, i_{2}, i_{3}$ (for $3 \#$ PFC) and $i_{\text {pet }}$ (for PET) and then use it as the current reference $i^{*}$ in (4) and (5) to share the power flow between $3 \#$ PFC and the PET, which can be expressed as

$$
\begin{array}{r}
i_{3 p e t}^{*}=\left(i_{1} \cdot s_{1}+i_{2} \cdot s_{2}+i_{3} \cdot s_{3}+i_{p e t} \cdot s_{p e t}\right) \\
/\left(s_{1}+s_{2}+s_{3}+s_{p e t}\right)
\end{array}
$$

In this case, the weighted-average power flow of 3\# PFC and the PET are forced to be equal with that of $1 \#$ PFC and 2\# PFC.

- If both 1\# PFC and 2\# PFC are in fault, the battery storage now maintains the DC bus voltage and uses (8) to restore the DC-bus voltage deviation. In this case, the average current of $i_{3}, i_{\text {pet }}$, and $i_{\text {bat }}$ (for the battery storage) is calculated and utilized as the current references for $3 \#$ PFC and the PET, which is written as

$$
\begin{array}{r}
i_{3 p e t}^{*}=\left(i_{3} \cdot s_{3}+i_{p e t} \cdot s_{p e t}+i_{b a t} \cdot s_{b a t}\right) \\
/\left(s_{3}+s_{\text {pet }}+s_{\text {bat }}\right) .
\end{array}
$$

In this case, the weighted power flow of the battery is forced to be equal with that of $3 \#$ PFC and the PET, which is aimed to reduce the their stress.

- If at least one of 1\# PFC and 2\# PFC works well, the battery storage adopts the SOC control. If the SOC exceeds its upper limit, or falls its lower limit, a specific positive or negative $i^{*}$ is assigned in (4) for the storage battery to discharge/charge itself. Otherwise, if the SOC is within the normal range, a ZERO $i^{*}$ will be fed into (4) to make the battery work in the floating mode.

- $\quad$ For each PV source, the power dispatching command are given as

$$
\begin{array}{r}
P_{\text {pvcmd }}=\min \left(P_{\text {pvcmd_PFC1 } 1}, P_{\text {pvcmd_PFC } 2},\right. \\
\left.P_{\text {pvcmd_PFC } 3}, P_{\text {pvcmd_PET }}\right)
\end{array}
$$

(2) AC Bus-sectionalized Mode

The key point of AC Bus-sectionalized mode is sharing the power between 3\# PFC and the PET, in addition to sharing power among 1\# PFC, 2\# PFC, and the battery storage. Meanwhile, proper SOC control should be applied to the battery storage as well. The detailed control algorithm for AC bus-sectionalized mode is elaborated as follows.

- $\quad$ Use (6) and (7) for 3\# PFC to restore 2\# AC bus's voltage and frequency to the rated value.

- $\quad$ Calculate the weighted average current of $i_{3}$ and $i_{\text {pet }}$, and then use it as the current reference in (5) for the PET to share the power flow between 3\# PFC and the PET.

- If the SOC is in normal range, the battery storage helps to restore the DC-bus voltage to reduce the stress of $1 \#$ PFC and 2\# PFC, as the fluctuation of the generation or the load consumption is taken by this three in this case.

- $\quad$ To realize the SOC control of the battery, the supervisory current reference for $1 \#$ PFC and 2\# PFC is given as

$$
i_{12}^{*}=\left\{\begin{array}{l}
\left(i_{1} \cdot s_{1}+i_{2} \cdot s_{2}+i_{b a t} \cdot s_{b a t}-i_{b a t}^{*}\right) /\left(s_{1}+s_{2}\right), \\
\text { if } \quad S O C \geq S O C_{\text {upper }} ; \\
\left(i_{1} \cdot s_{1}+i_{2} \cdot s_{2}+i_{b a t} \cdot s_{b a t}+i_{b a t}^{*}\right) /\left(s_{1}+s_{2}\right), \\
\text { if } \quad S O C \leq S O C_{\text {lower }} ; \\
\left(i_{1} \cdot s_{1}+i_{2} \cdot s_{2}+i_{b a t} \cdot s_{b a t}\right) /\left(s_{1}+s_{2}\right), \text { else. }
\end{array}\right.
$$

Consequently, the battery discharges/charges with the specified current $i_{\text {bat }}^{*}$ if its SOC exceeds/falls below its upper/lower limit. In these two cases, the battery will not 
participate in the DC bus voltage restoration. Otherwise, the battery will maintain the DC bus voltage in the floating (ZERO power) mode, as well as restore it.

- $\quad$ For each PV source, the power dispatching command is given as

$$
\begin{aligned}
& P_{\text {pvcmd }}=\min \left(P_{\text {pvcmd_PFC1 }}, P_{\text {pvcmd_PFC2 }},\right. \\
& P_{\text {pvcmd_BAT }} \text { ) }
\end{aligned}
$$

(3) DC Bus-sectionalized Mode

In DC bus-sectionalized mode, similar to AC bus-sectionalized mode, proper power sharing between 1\# PFC and 2\# PFC is needed. The SOC control is adopted by the storage as well. The detailed control algorithm for DC bus-sectionalized mode is elaborated as follows.

- Use (8) to regulate $\delta v_{D C}$ for $1 \#$ PFC and $2 \#$ PFC to restore the DC-bus voltage. Calculate average current $\left(i_{12}^{*}\right)$ of $i_{1}$ (for $1 \#$ PFC) and $i_{2}$ (for 2\# PFC) and use it as the current reference $i^{*}$ in (4) to share their output power.

- The battery storage maintains the voltage of $2 \#$ DC bus by the droop control in (1) and restores it to the rated value by (8).

- To realize the SOC control of the battery, the supervisory current reference for 3\# PFC and the PET is given as

$$
i_{3 p e t}^{*}=\left\{\begin{array}{l}
\left(i_{3} \cdot s_{3}+i_{\text {pet }} \cdot s_{\text {pet }}+i_{\text {bat }} \cdot s_{\text {bat }}-i_{\text {bat }}^{*}\right) \\
/\left(s_{3}+s_{\text {pet }}\right), \quad \text { if } \quad S O C \geq S O C_{\text {upper }} ; \\
\left(i_{3} \cdot s_{3}+i_{\text {pet }} \cdot s_{\text {pet }}+i_{\text {bat }} \cdot s_{\text {bat }}+i_{b a t}^{*}\right) \\
/\left(s_{3}+s_{p e t}\right), \quad \text { if } \quad S O C \leq S O C_{\text {lower }} ; \\
\left(i_{3} \cdot s_{3}+i_{\text {pet }} \cdot s_{\text {pet }}+i_{\text {bat }} \cdot s_{\text {bat }}\right) \\
/\left(s_{3}+s_{\text {pet }}\right), \quad \text { else. }
\end{array}\right.
$$

Consequently, the battery discharges/charges with the specified current $i_{b a t}^{*}$ if its SOC exceeds/falls below its upper/lower limit. Otherwise, the battery will maintain the DC-bus voltage in the floating (ZERO power) mode.

- For PV sources connected to the 1\# DC bus, the power dispatching command is given as

$$
P_{\text {pvcmd }}=\min \left(P_{\text {pvcmd_PFC1 }}, P_{\text {pvcmd_PFC2 }}\right) .
$$

For PV sources connected to the 2\# DC bus, the power dispatching command is given as

$$
P_{\text {pvcmd }}=\min \left(P_{\text {pvcmd_PFC3 }}, P_{\text {pvcmd_PET }}\right) \text {. }
$$

(4) Islanded Mode

In the islanded mode, stabilization is the primary task, so the PV power dispatching is quite crucial. The detailed control algorithm for DC bus-sectionalized mode is elaborated as follows:

- Use (8) to regulate $\delta v_{D C}$ for $1 \#$ PFC and 2\# PFC to restore the 1\# DC-bus voltage. Calculate average current $\left(i_{12}^{*}\right.$ ) of $i_{1}$ (for 1\# PFC) and $i_{2}$ (for 2\# PFC) and use it as the current reference $i^{*}$ in (4) to share their output power.

- Use (8) to regulate $\delta v_{D C}$ for the battery to restore the 2\# DC-bus voltage.

- $\quad$ Use (6) and (7) for 3\# PFC to restore 2\# AC bus's voltage and frequency to their rated values.

- Calculate the weighted average current of $i_{3}$ and $i_{\text {pet }}$, and then use it as the current reference in (5) for the PET to share the power flow between 3\# PFC and the PET.

- For PV sources connected to the 1\# DC bus, the power dispatching command is given as

$$
P_{\text {pvcmd }}=\min \left(P_{\text {pvcmd_PFC1 }}, P_{\text {pvcmd_PFC2 }}\right) \text {. }
$$


For PV sources connected to the 2\# DC bus, the power dispatching command is given as

$$
P_{\text {pvcmd }}=\min \left(P_{\text {pvcmd_BAT }}, P_{\text {pvcmd_SOC }}\right) \text {. }
$$

Note that in case of a fault on a section, the PFC converters connecting the damaged section (DC or AC) should be also switched off in addition to the sectionalized breaker. With the help of device state signal ( $s_{\text {device-index }}$ symbols in the equations), the secondary control layer could totally handle such situations autonomously and make sure that other undamaged sections operate well.

\subsubsection{Seamless Mode Switching}

Generally, a proportional-integral controller is adopted for no steady-state error control in the secondary layer. At this point, for different BSHMG operational modes, although different corresponding control strategies are executed, the secondary strategy needs to switch the state of the controller's integrator as little as possible, and try not to introduce unnecessary step changes.

The seamless switching scheme for the BSHMG is illustrated as follows.

(1) Switching from the grid-connected mode to the AC-bus sectionalized mode

The core target for seamless switching from grid-connected mode to AC-bus sectionalized mode is to avoid power rushes on the AC breaker. The secondary control layer will transfer the power flow on the AC breaker to the 3\# PFC and the PET to achieve that, as depicted in Figure 3:

- $\quad$ Calculate the weighted-average current of $i_{1}, i_{2}$, and $i_{b a t}$, and use it as the current reference $i^{*}$ in (4) to share the output power among 1\# PFC, 2\# PFC, and the battery.

- $\quad$ Make 3\# PFC and the PET to undertake the power flow of the AC breaker, so the current reference for $3 \# \mathrm{PFC}$ and the PET is given as

$$
i_{3 p e t}^{*}=\left(i_{3} \cdot s_{3}+i_{p e t} \cdot s_{p e t}+i_{a c b r}\right) /\left(s_{3}+s_{p e t}\right),
$$

where $i_{a c b r}$ is the current passing the AC breaker, with the positive direction defined as passing from $1 \#$ AC bus to $2 \#$ AC bus.

- If the passing power flow in the $\mathrm{AC}$ breaker meets the requirements of opening it. The $\mathrm{AC}$ breaker then receive the open command to execute the opening operation.

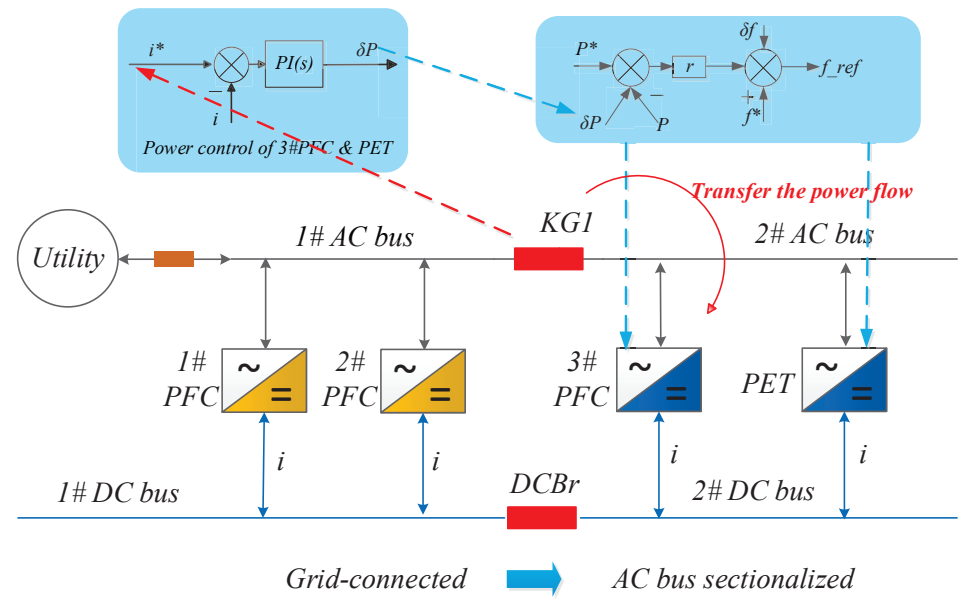

Figure 3. The control diagram from grid-connected mode to AC bus sectionalized mode.

(2) Switching from the AC-bus sectionalized mode to the islanded mode

To switch from AC-bus sectionalized mode to the islanded mode seamlessly, the battery can not share its output power with other PFCs, but to reduce the power flow on the DC breaker to zero, as depicted in Figure 4. 
- Calculate the weighted average current of $i_{1}$ and $i_{2}$ and then use it as the current reference to share the power flow between 1\# PFC and 2\# PFC.

- Make the battery to undertake the power flow of the DC breaker, so the battery does not share its output power with 1\# PFC and 2\# PFC any more and the current reference for the battery is given as

$$
i_{b a t}^{*}=i_{d c b r}
$$

where $i_{d c b r}$ is the current passing the DC breaker, with the positive direction defined as passing from $1 \#$ DC bus to $2 \#$ DC bus.

- If the passing power flow in the DC breaker meets the requirements of cutting off, the $\mathrm{DC}$ breaker then receives the open command to execute the opening operation.

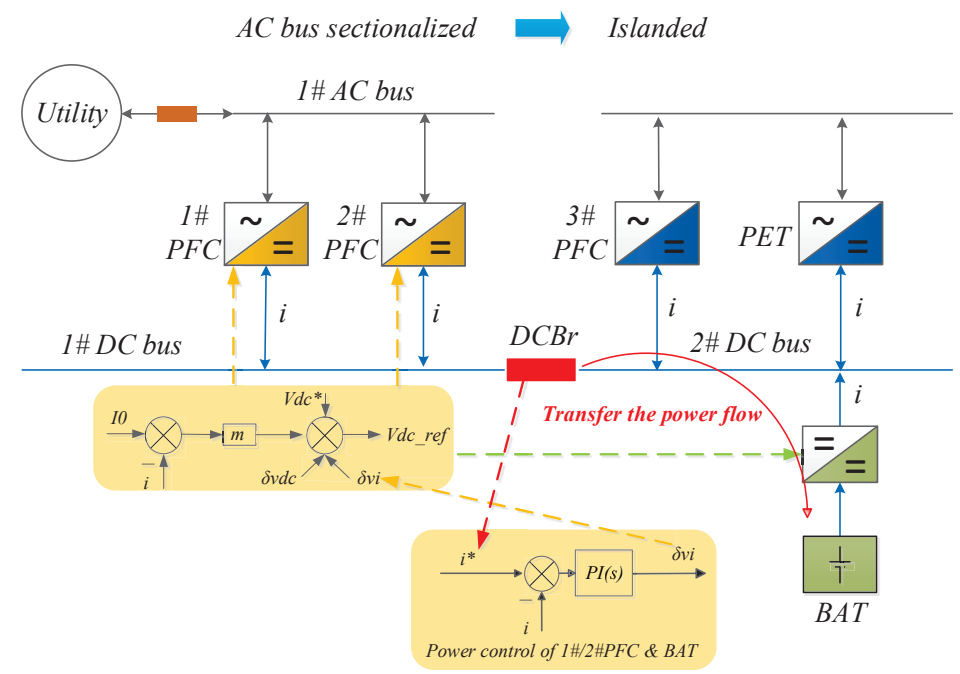

Figure 4. The control diagram from AC-bus sectionalized mode to islanded mode.

(3) Switching from the grid-connected mode to the DC-bus sectionalized mode

The core target for seamless switching from grid-connected mode to DC-bus sectionalized mode is to avoid power rush on the DC breaker. The secondary control layer will transfer the power flow on the DC breaker to the 3\# PFC and the PET to achieve that, as depicted in Figure 5:

- Give the ZERO current reference for the storage battery to make it work in the floating mode.

- Make 3\# PFC and the PET to undertake the power flow of the DC breaker. Calculate the weighted average current of $i_{3}, i_{\text {pet }}$, and $i_{d c b r}$ for 3\# PFC and the PET, and then use it as the current reference for $3 \#$ PFC and the PET in (4) and (5).

- If the passing power flow in the DC breaker meets the requirements of cutting-off. The DC breaker then receive the open command to execute the opening operation. 


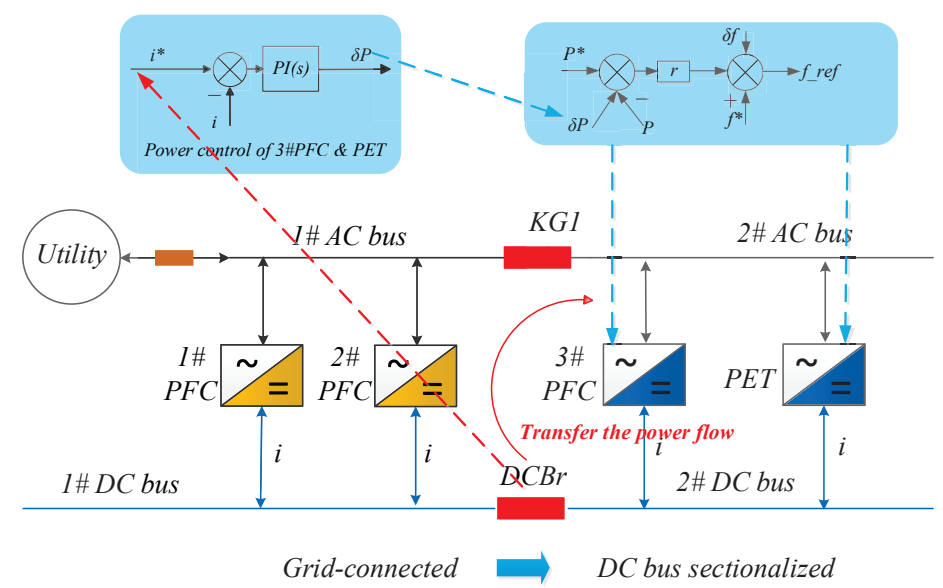

Figure 5. The control diagram from grid-connected mode to DC bus sectionalized mode.

(4) Switching from the DC-bus sectionalized mode to the islanded mode

In this case, the 3\# PFC and PET also need to undertake the power flow on the AC breaker, as depicted in Figure 6.

- $\quad$ The current reference for $3 \#$ PFC and the PET is given as

$$
i_{3 p e t}^{*}=\left(i_{3} \cdot s_{3}+i_{p e t} \cdot s_{p e t}+i_{a c b r}\right) /\left(s_{3}+s_{p e t}\right),
$$

where $i_{a c b r}$ is the current passing the AC breaker, with the positive direction defined as passing from $1 \# \mathrm{AC}$ bus to $2 \# \mathrm{AC}$ bus.

- If the passing power flow in the $\mathrm{AC}$ breaker meets the requirements of opening it, the $\mathrm{AC}$ breaker then receives the open command to execute the opening operation.

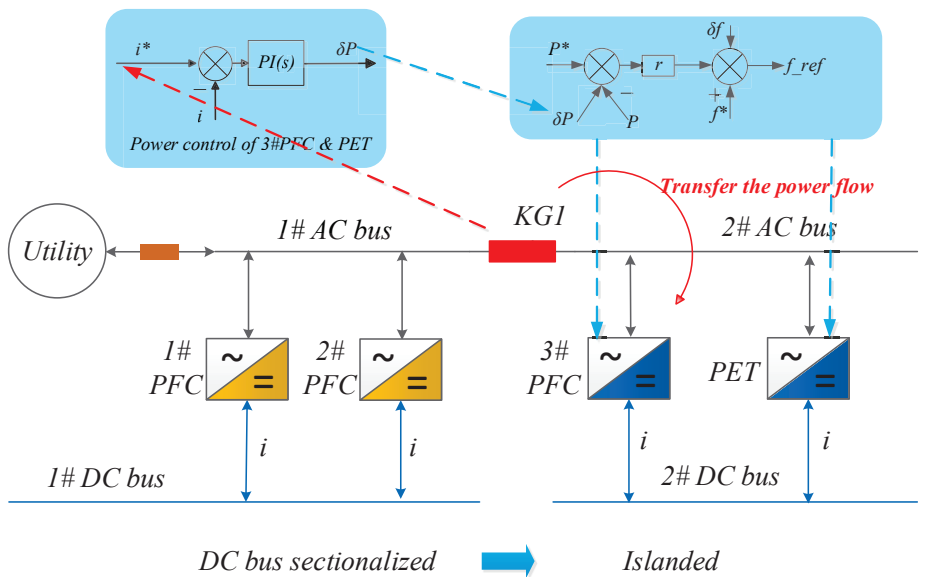

Figure 6. The control diagram from the DC bus sectionalized mode to islanded mode.

Note that although only two control layers-the primary control and the secondary control-are presented in this paper, it is not to say that no tertiary control can be added in this hierarchical system. In fact, generally, a power management strategy in the tertiary control level could perfectly adapt the proposed coordination control strategy; however, it is beyond the scope of this paper.

\section{Experimental Study}

\subsection{System Configuration}

The proposed standardization-oriented hierarchical control strategy is practically applied to the demonstration project of a bus-sectionalized hybrid AC/DC microgrid in Shaoxing, Zhejiang Province, China. The demonstration hybrid microgrid locates in 
the industrial park named "Shijihuatong" in Shangyu District of Shaoxing. The satellite photo of the park from Google Maps is shown in Figure 7. The structure of the bussectionalized hybrid AC/DC microgrid is shown in Figure 8. In the park, the PV arrays on the factory's roofs are the main distributed generation and the inductors of the injection molding machines are connected to DC bus and they are driven by DC/AC converters, with the former AC/DC conversion stage being removed for higher efficiency. The lightemitting diode (LED) lighting and the charging piles of the electric vehicles are other DC loads. By integrating the DC loads and DC distributed sources in a DC bus, integrating the $\mathrm{AC}$ loads and $\mathrm{AC}$ distributed sources in an $\mathrm{AC}$ bus, and interlinking the $\mathrm{AC}$ bus and the DC bus through bidirectional AC/DC converters and the PET, the hybrid AC/DC microgrid is constructed, and its reliability, power quality, and operation flexibility are all get significantly improved. Table 2 summarizes the major components in the hybrid microgrid. Figure 9 shows some photos of the actual system. The control cycle of the supervisory control is $50 \mathrm{~ms}$. The project adopts GOOSE communication because the time delay is very import for the static operation and mode transition. The main influence of the communication time delay is on the power flow control of the inverters to achieve mode transitions. That is because the main power regulation references given by the secondary layer in mode transition is $\delta v i$ (or $\delta P$ ), which decides the operating points of inverters but has less influence on the system stability. Even so, that is not to say the time delay is less important as it has obvious influence on voltage/frequency restoration and the control cycle period of the secondary layer as well. The control parameters used in the supervisory control and primarily control are not listed due to the space limitation.

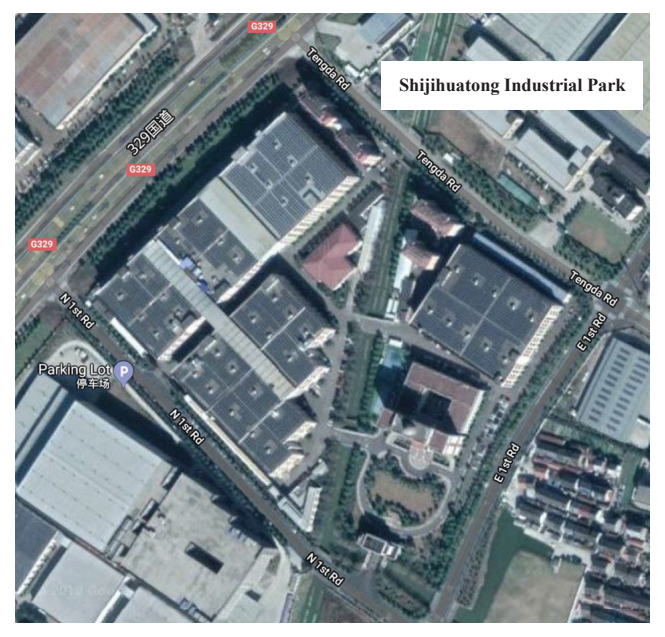

Figure 7. The satellite photo of Shijihuatong industrial park.

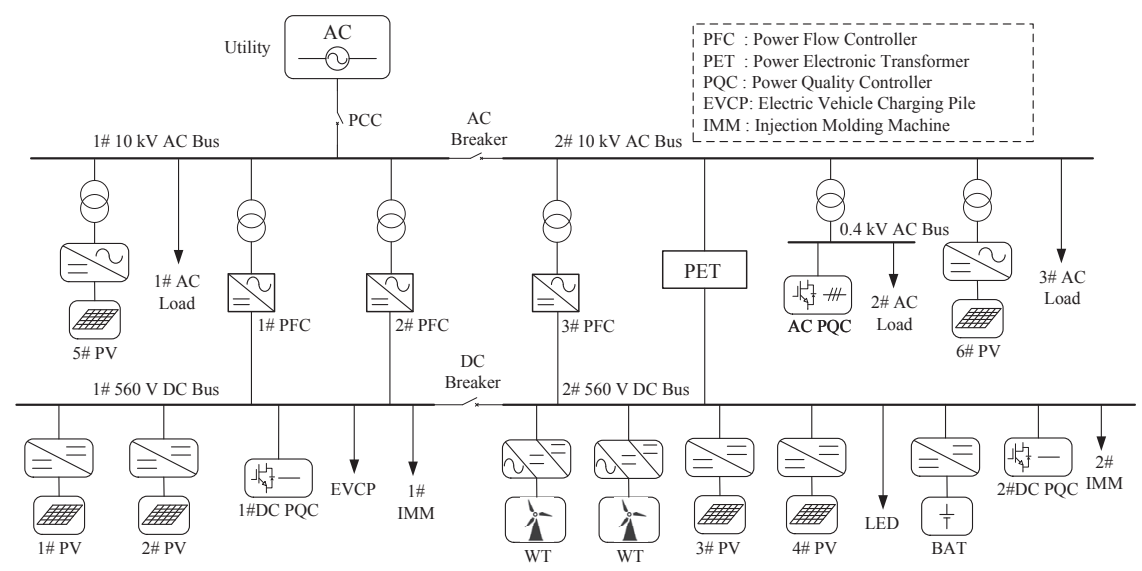

Figure 8. Schematic diagram of the bus-sectionalized hybrid microgrid in Shijihuatong industrial park. 


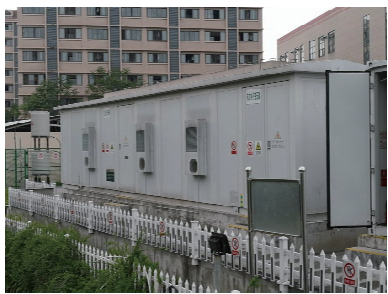

Power Electronic Transformer

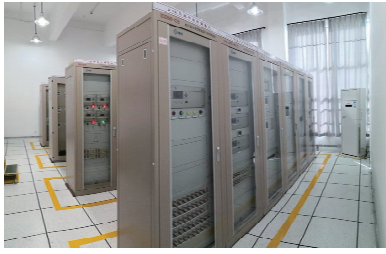

Secondary \& Supervision System

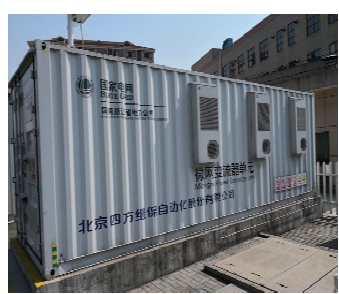

Battery DC/DC Converter

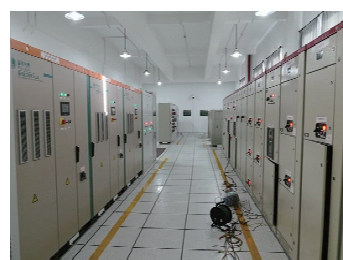

Power Flow Controller \& Breakers \& Transformers

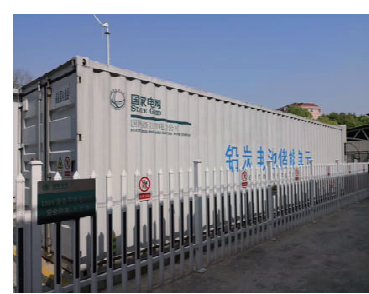

Lead-carbon Batteries

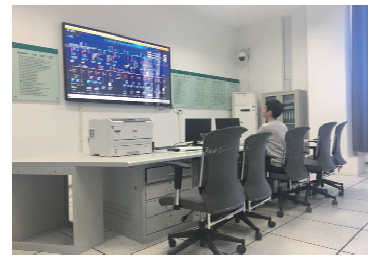

Central Control Room

Figure 9. Photos of the bus-sectionalized hybrid AC/DC microgrid.

Table 2. Components of the hybrid microgrid.

\begin{tabular}{|c|c|c|}
\hline Abbreviation & Full Name & Capacity \\
\hline $\begin{array}{l}\text { 1\# PFC } \\
\text { 2\# PFC } \\
\text { 3\# PFC }\end{array}$ & $\begin{array}{l}\text { Power Flow } \\
\text { Controller }\end{array}$ & $\begin{array}{l}250 \mathrm{kVA} \\
250 \mathrm{kVA} \\
250 \mathrm{kVA}\end{array}$ \\
\hline PET & $\begin{array}{l}\text { Power Electronic } \\
\text { Transformer }\end{array}$ & $250 \mathrm{kVA}$ \\
\hline $\begin{array}{l}\text { 1\# PV } \\
\text { 2\# PV } \\
\text { 3\# PV } \\
\text { 4\# PV } \\
\text { 5\# PV } \\
\text { 6\# PV }\end{array}$ & Photovoltaic Source & $\begin{array}{c}96 \mathrm{kWp} \\
235 \mathrm{kWp} \\
270 \mathrm{kWp} \\
270 \mathrm{kWp} \\
520 \mathrm{kWp} \\
520 \mathrm{kWp}\end{array}$ \\
\hline $\begin{array}{c}\text { BAT } \\
1 \# 1 \mathrm{MM} \\
2 \# 1 \mathrm{MM}\end{array}$ & $\begin{array}{l}\text { Lead-carbon Batteries } \\
\text { Injection Molding } \\
\text { Machine Load }\end{array}$ & $\begin{array}{c}4 \mathrm{~h} 250 \mathrm{~kW} \\
5 * 50 \mathrm{~kW} \\
5 * 50 \mathrm{~kW} \\
\end{array}$ \\
\hline EVCP & $\begin{array}{l}\text { Electric Vehicle } \\
\text { Charging Pile }\end{array}$ & $8 * 60 \mathrm{~kW}$ \\
\hline $\begin{array}{l}\text { 1\# DC Pdc } \\
\text { 2\# DC Pdc }\end{array}$ & $\begin{array}{c}\text { DC Power } \\
\text { Quality Controller }\end{array}$ & $50 \mathrm{~A}$ \\
\hline AC Pdc & Power Quality Controller & $150 \mathrm{~A}$ \\
\hline $\begin{array}{l}\text { 1\# WT } \\
\text { 2\#WT }\end{array}$ & Wind Turbine & $\begin{array}{l}5 \mathrm{~kW} \\
5 \mathrm{~kW}\end{array}$ \\
\hline LED & Light-emitting Diode & $50 \mathrm{~kW}$ \\
\hline
\end{tabular}

\subsection{Voltage Grade Set}

The AC voltage for $1 \#$ and $2 \#$ AC bus is set to be $10 \mathrm{kV}$ to connect the AC bus to local distributed network directly and supply for $10 \mathrm{kV}$ AC load. There is also a $0.4 \mathrm{kV}$ AC bus for common power load. Different from most other low-voltage DC microgrids, the DC bus voltage is set to be $560 \mathrm{~V}$ in this demonstrative project. The authors hypothesize that the $560 \mathrm{~V} \mathrm{DC}$ voltage grade is more easily applied and popularized. The reasons can be summarized as the following four aspects: 
1. Economy: The insulation and protection of the $560 \mathrm{Vdc}$ voltage grade is the same as that of the 380 Vac voltage grade. Thus, most of the current produced cables, breakers, and switches can be applied to the $560 \mathrm{Vdc}$ voltage grade directly.

2. Compatibility: Compatibility is a key factor of the $560 \mathrm{Vdc}$ voltage grade. Currently, most of the power loads adopt the variable frequency drive technology. The realization of the direct DC power supply for these variable frequency drivers is the greatest advantage of DC distribution networks. The $560 \mathrm{Vdc}$ voltage grade is compatibility with current $D C$ voltage grade of most $\mathrm{AC} / \mathrm{DC} / \mathrm{AC}$ variable frequency drivers.

3. Adaptability: Taking distributed generation into consideration, the $560 \mathrm{Vdc}$ voltage grade can easily meet the need of $380 \mathrm{Vac}$ inversion. Thus, $560 \mathrm{Vdc}$ fits the requirement for integration of PV sources and batteries very well.

\subsection{Multimode Operation Study}

In the current experiment, the DC-side currents of 1\# PFC, 2\#PFC, 3\# PFC, the PET, and the battery are recorded by the recorder of YOKOGAWA DL850. The voltages of the 1\# DC-bus and 2\# DC-bus are recorded by YOKOGAWA DL850 as well. The three-phase AC voltage of 2\# AC bus is displayed by the oscilloscope of Agilent DOS-X 2022A. The power flow of the AC breaker and the DC breaker is sampled from the supervisory system of the microgrid.

The following cases are studied to verify the effectiveness of control strategy in multimode operation of the bus-sectionalized hybrid AC/DC microgrid. Totally, four different operation modes are studied, including grid-connected mode, AC bus-sectionalized mode, DC bus-sectionalized mode, and islanded mode. In each case, 3\# PV is cut off from 2\# DC bus to emulate a sudden step change of generation or the load in the system. Figures 10-13 show the currents of the battery, 1\# PFC, 2\# PFC, 3\# PFC, and the PET in the four cases, respectively. Figure 14 and Figure 15 show the voltages of 1\# DC bus and 2\# DC bus in DC bus-sectionalized mode and islaned mode, respectively. The according results are illustrated as follows:

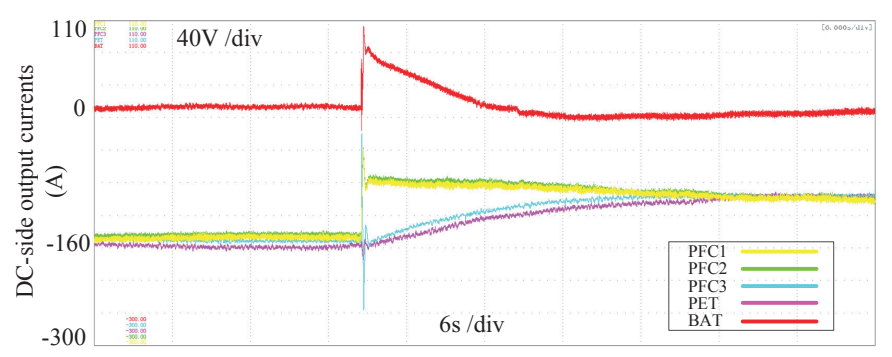

Figure 10. DC-side output currents. Yellow line for 1\# PFC, green line for 2\# PFC, blue line for 3\#PFC, pink line for the PET, and red line for the battery.

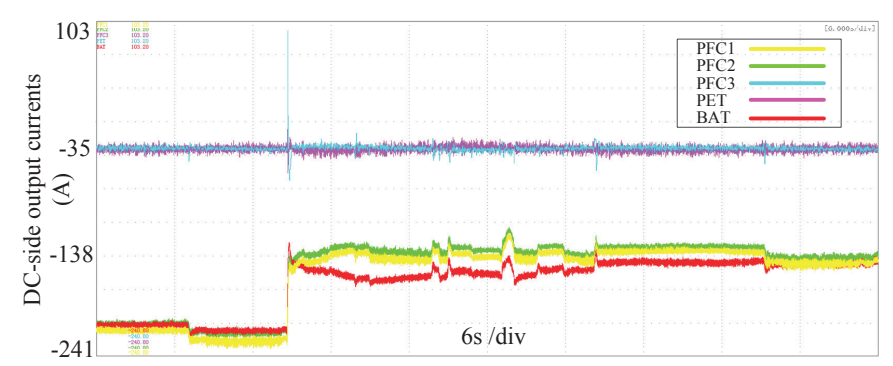

Figure 11. DC-side output currents. Yellow line for 1\# PFC, green line for 2\# PFC, blue line for 3\#PFC, pink line for the PET, and red line for the battery. 


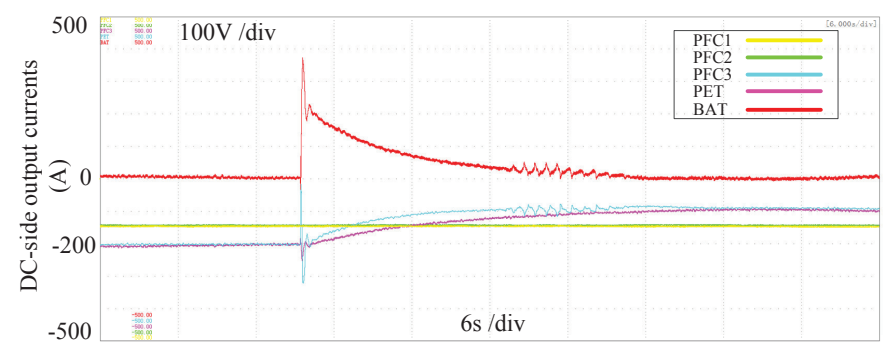

Figure 12. DC-side output currents. Yellow line for $1 \#$ PFC, green line for 2\# PFC, blue line for 3\#PFC, pink line for the PET, and red line for the battery.

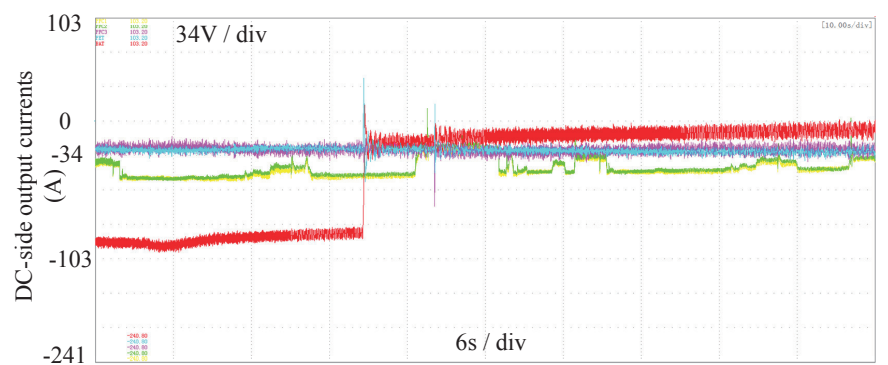

Figure 13. DC-side output currents. Yellow line for 1\# PFC, green line for 2\# PFC, blue line for 3\# PFC, pink line for the PET, and red line for the battery.

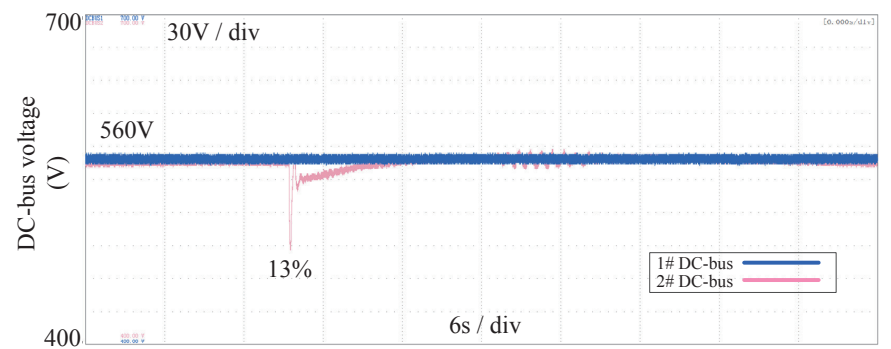

Figure 14. DC-bus voltage. Blue line for 1\# DC-bus voltage, pink line for 2\# DC-bus voltage.

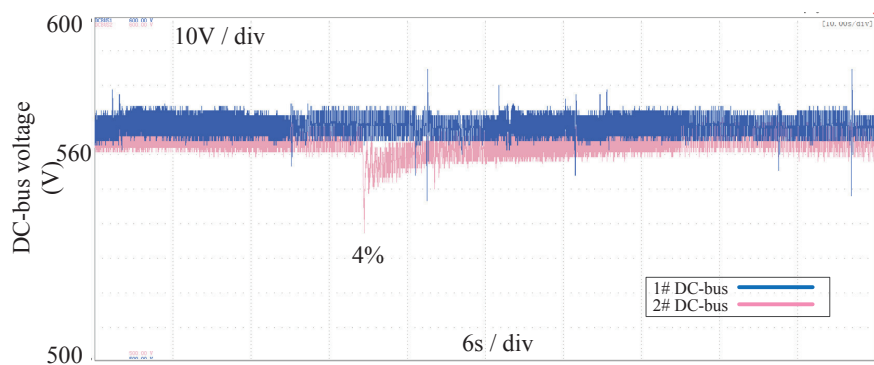

Figure 15. DC-bus voltage. Blue line for 1\# DC-bus voltage, pink line for 2\# DC-bus voltage.

\section{Case1: Grid-connected Operation}

In the experiment, 3\# PV output power is $\sim 120.3 \mathrm{~kW}(209.47 \mathrm{~A})$. The following can be observed in Figure 10: (1) In steady state of grid-connected operation mode, the battery's charging current remains at ZERO if the SoC is in the "normal" range. (2) All the DC voltage support components means the battery, $1 \#$ PFC, and 2\# PFC act when the sudden load change happens. (3) The output current is shared among 1\# PFC, 2\# PFC, 3\# PFC, and the PET. Only small mismatches can be observed.

Case2: AC bus-sectionalized Operation

In the experiment, $3 \#$ PV's output power is $\sim 127.47 \mathrm{~kW}$. The following can be observed in Figure 11: (1) In steady state of AC bus-sectionalized operation mode, the battery shares its output current with 1\#PFC and 2\# PFC. (2) All the DC voltage support components, means the battery, 1\# PFC and 2\# PFC acts when the sudden load change happens. (3) 
The output current is shared between 3\# PFC and the PET. Only small mismatches can be observed.

\section{Case3: DC bus-sectionalized Operation}

In the experiment, 3\# PV's output power is about $124.2 \mathrm{~kW}(218.01 \mathrm{~A})$. The following can be observed in Figures 12 and 14: (1) In steady state of DC-bus sectionalized operation mode, the battery's charging current remains at ZERO if the SoC is in the "normal" range. (2) 1\# PFC shares its output current with 2\# PFC while 3\# PFC shares its output current with the PET. (3) The DC-bus voltage of $2 \#$ DC bus is maintained at $560 \mathrm{~V}$ by the battery.

\section{Case4: Islanded Operation}

In the experiment, 3\# PV's output power is $\sim 39 \mathrm{~kW}$. It can be observed in Figures 13 and 15: (1) In steady state of islanded operation mode, 1\# PFC shares its output current with 2\# PFC, while 3\# PFC shares its output current with the PET. (2) The voltage of 2\# DC-bus is maintained at $560 \mathrm{Vdc}$ and the battery's output power tracks the load fluctuation.

\subsection{Seamless Mode Switching Study}

This subsection shows the test cases in which operation modes of the bus-sectionalized hybrid microgrid are actively switched. The mode switching command comes from the supervisory control and the according results are illustrated as follows.

\section{Case1: From Grid-connected Mode to AC bus-sectionalized Mode}

Figure 16a illustrates the AC breaker power in the active switching from the gridconnected mode to the AC-bus sectionalized mode. Figure 16c shows the response of AC voltage of the 2\# AC-bus. The AC breaker power is $\sim 126.68 \mathrm{~kW}$ at first and then it is controlled to be ZERO by 3\# PFC and the PET. When the AC breaker power is less than $10 \mathrm{~kW}$, the MGCC opens the AC breaker, completing the seamless transfer from grid-connected mode to the AC-bus sectionalized mode. No large transients are observed in the transfer procedure.

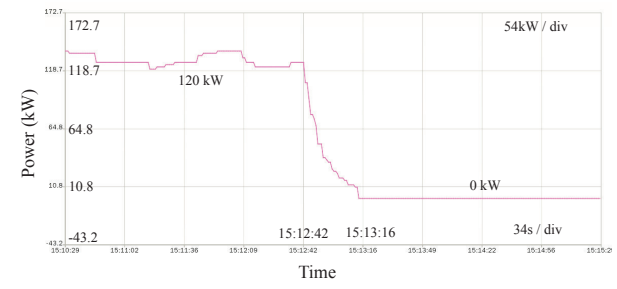

(a) Power flow of the AC breaker during active switching from the grid-connected mode to the ACbus sectionalized mode.

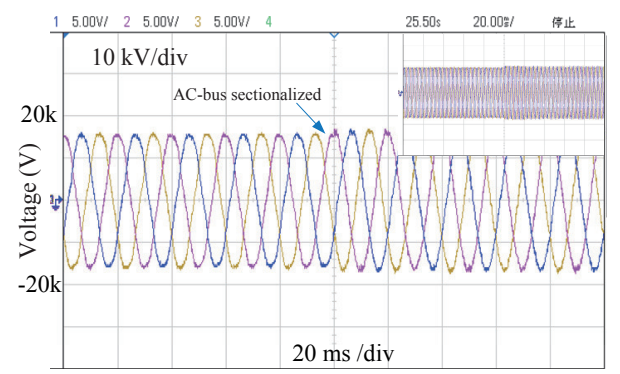

(c) Voltage of 2\# AC-bus during active switching from the grid-connected mode to the AC-bus sectionalized mode.

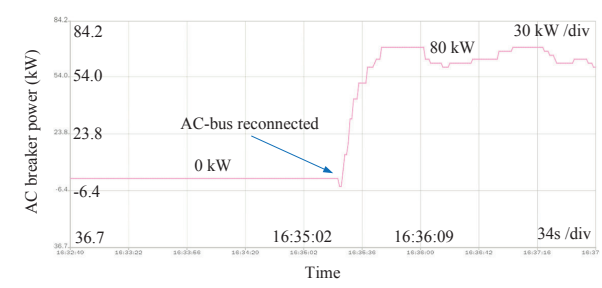

(b) Power flow of the AC breaker during active switching from the islanded mode to the DC bus sectionalized mode.

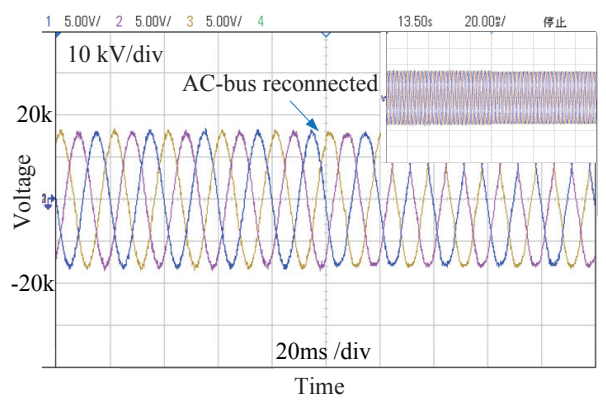

(d) Voltage of 2\# AC-bus during active switching from the islanded mode to the DC bus sectionalized mode.

Figure 16. Cont. 


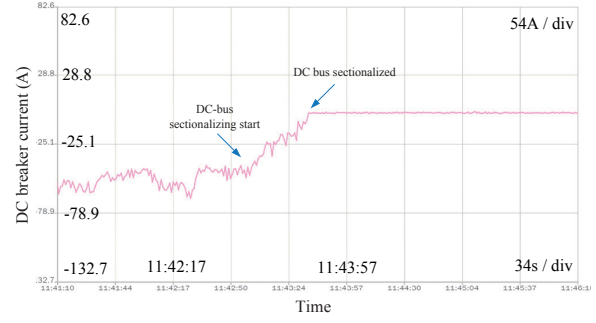

(e) Power flow of the DC breaker during active switching from the AC-bus sectionalized mode to islanded mode.

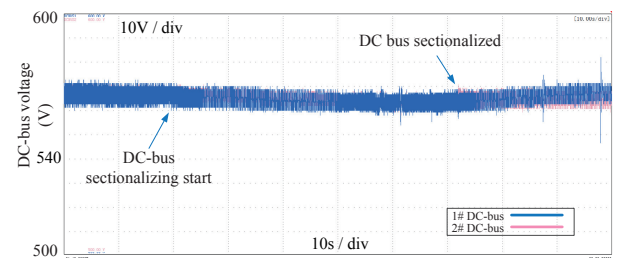

(g) DC-bus voltages during active switching from the AC-bus sectionalized mode to islanded mode. Blue line for 1\# DC-bus voltage, pink line for 2\# DC-bus voltage.

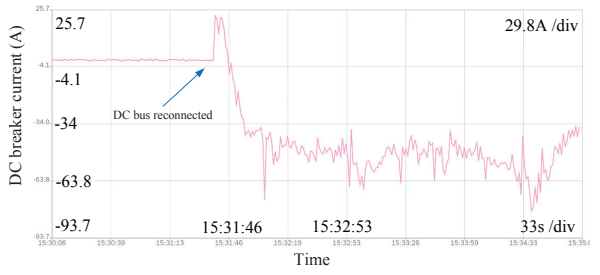

(f) Power flow of the DC breaker during active switching from the DC-bus sectionalized mode to the grid-connected mode.

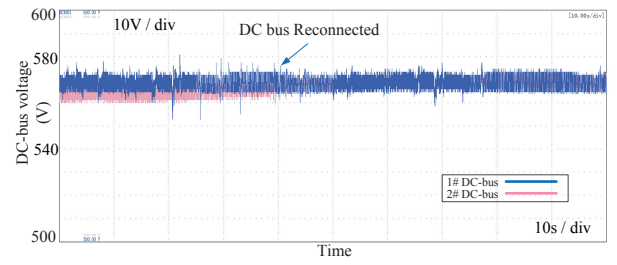

(h) DC-bus voltages during active switching from the DC-bus sectionalized mode to the gridconnected mode. Blue line for 1\# DC-bus voltage, pink line for 2\# DC-bus voltage.

Figure 16. Experimental results of seamless switching, Part I.

\section{Case2: From AC bus-sectionalized Mode to Islanded Mode}

Figure 16e illustrates the DC breaker power flow in the active switching from the AC-bus sectionalized mode to the islanded mode. Figure $16 \mathrm{~g}$ shows the response of DC voltage. The DC breaker current is approximately $-42.3 \mathrm{~A}$ at first and then it is controlled to be ZERO by the battery. When the DC breaker power is less than $10 \mathrm{~kW}$, the MGCC opens the DC breaker, completing the seamless transfer from the AC-bus sectionalized mode to the islanded mode. No large transients are observed in the transfer procedure.

\section{Case3: From Islanded Mode to DC Bus-sectionalized Mode}

Figure 16b illustrates the AC breaker power in the active switching from the islanded mode to the AC-bus sectionalized mode. Figure 16d shows the AC voltage of 2\# AC-bus. 3\# PFC executes the synchronization between 2\# AC bus and 1\# AC bus. The control logic is pretty much in line with the logic design in Section 3C. No large transients are observed in the transfer procedure.

Case4: From DC Bus-sectionalized Mode to Grid-connected Mode Figure 16f illustrated the AC breaker power in the active switching from AC-bus sectionalized mode to the grid-connected mode. Figure 16h shows the response of DC voltage. The battery executes the synchronization between 2\# DC bus and 1\# DC bus. The control logic is pretty much in line with the logic design in Section 3C. No large transients are observed in the transfer procedure.

\section{Case5: From Grid-connected Mode to DC Bus-sectionalized Mode}

Figure 17a illustrates the DC breaker power in the active switching from the gridconnected mode to the DC-bus sectionalized mode. Figure 17c shows the response of DC voltage. The DC breaker current is approximately $-53.1 \mathrm{~A}$ at first and then it is controlled to be ZERO by 3\# PFC and the PET. When the DC breaker power is less than $10 \mathrm{~kW}$, the MGCC opens the DC breaker, completing the seamless transfer from grid-connected mode to the DC-bus sectionalized mode. No large transients are observed in the transfer procedure. 


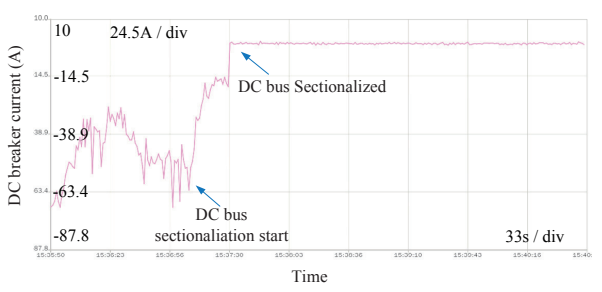

(a) Power flow of the DC breaker during active switching from the grid-connected mode to the DCbus sectionalized mode.

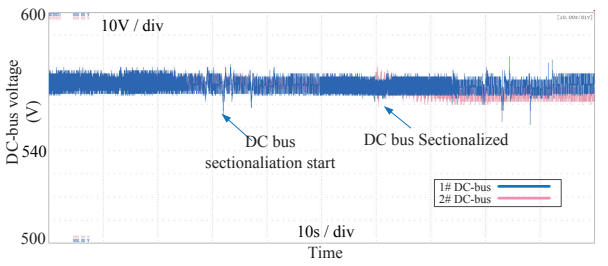

(c) DC-bus voltages during active switching from the grid-connected mode to the DC-bus sectionalized mode. Blue line for 1\# DC-bus voltage, pink line for 2\# DC-bus voltage.

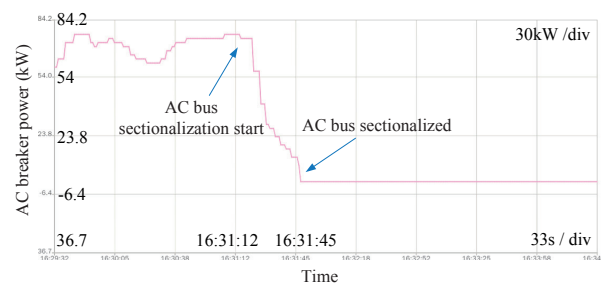

(e) Power flow of the DC breaker during active switching from the DC-bus sectionalized mode to the islanded mode.

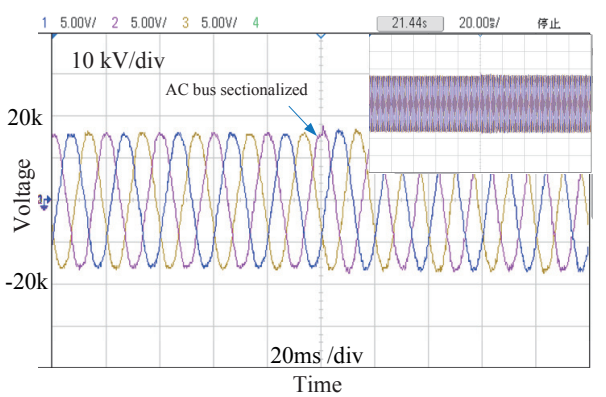

(g) Voltage of 2\# AC-bus during active switching from the DC-bus sectionalized mode to the islanded mode.

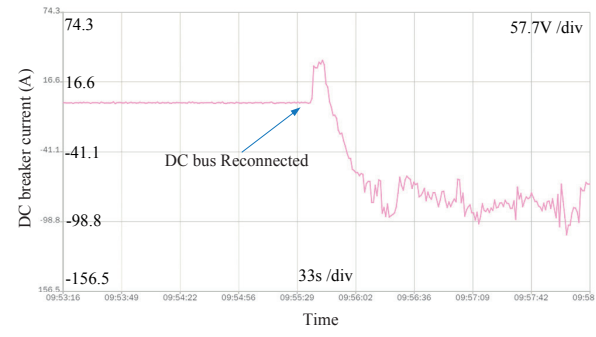

(b) Power flow of the DC breaker during active switching from the islanded mode to the AC-bus sectionalized mode.

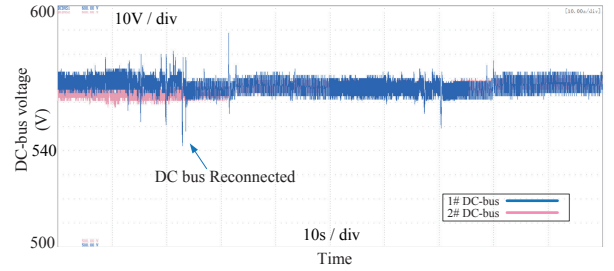

(d) DC-bus voltages during active switching from the islanded mode to the AC-bus sectionalized mode. Blue line for 1\# DC-bus voltage, pink line for 2\# DC-bus voltage.

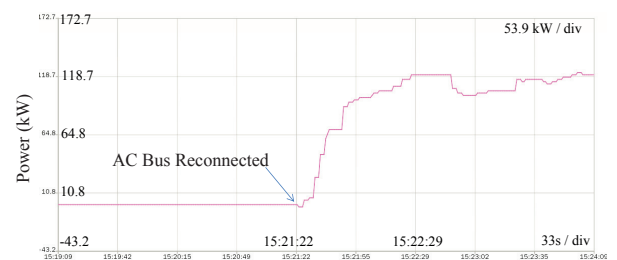

(f) Power flow of the AC breaker during active switching from the AC-bus sectionalized mode to grid-connected mode.

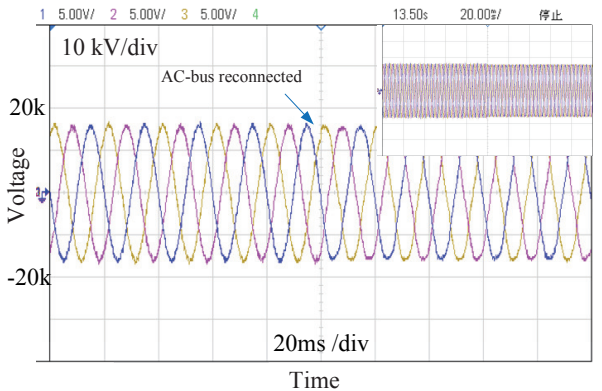

(h) Voltage of 2\# AC-bus during active switching from the AC-bus sectionalized mode to gridconnected mode.

Figure 17. Experimental results of seamless switching, Part II.

\section{Case6: From DC Bus-sectionalized Mode to Islanded Mode}

Figure 17e illustrates the DC breaker power flow in the active switching from the AC-bus sectionalized mode to the islanded mode, respectively. Figure $17 \mathrm{~g}$ shows the AC voltage of the $2 \#$ AC bus, respectively. The AC breaker power is $~ 73.9 \mathrm{~kW}$ at first and then it is controlled to be ZERO by $3 \#$ PFC and the PET. When the AC breaker power is less than $10 \mathrm{~kW}$, the MGCC opens the AC breaker, completing the seamless transfer from the DC-bus sectionalized mode to the islanded mode. No large transients are observed in the transfer procedure.

\section{Case7: From Islanded Mode to AC Bus-sectionalized Mode}


Figure $17 \mathrm{~b}$ illustrates the DC breaker power in the active switching from the islanded mode to the AC-bus sectionalized mode. Figure 17d shows the response of DC voltage. The battery executes the voltage synchronization between $2 \#$ DC bus and 1\# DC bus. The control logic is pretty much in line with the logic design in Section III C. No large transients are observed in the transfer procedure.

Case8: From AC Bus-sectionalized Mode to Grid-connected Mode

Figure $17 \mathrm{f}$ illustrates the AC breaker power in the active switching from AC-bus sectionalized mode to the grid-connected mode. Figure 17h shows the response of AC voltage of 2\# AC-bus, respectively. 3\# PFC executes the synchronization of 2\# AC bus and $1 \#$ AC bus. The control logic is pretty much in line with the logic design in Section III C. No large transients are observed in the transfer procedure.

\section{Conclusions}

This paper introduces the concept of a bus-sectionalized hybrid AC/DC microgrid and its standardization-oriented hierarchical control strategy. The bus-sectionalized configuration makes the hybrid AC/DC microgrid more reliable and flexible. The proposed control paradigm achieves seamless mode switching and uninterrupted power supply without controller reconfiguration.

A typical BSHMG with the proposed control paradigm was implemented in Shijihuatong, Shaoxing, Zhejiang Province, China, and it has been in full operation for years. The power supply reliability in the industrial park has been significantly improved. The rooftop PV generation has also been well utilized through the BSHMG. This success experience in Shijihuatong industrial park should be helpful and act as a good reference in developing future AC/DC hybrid distribution networks.

Author Contributions: Conceptualization, W.W., J.L., and H.C.; methodology, J.L. and H.C.; software, H.C. and J.L.; validation, J.L., P.Y. and H.C.; investigation, J.L.; resources, W.W.; data curation, P.Y.; writing - original draft preparation, J.L. and H.C.; writing-review and editing, J.L. and H.C.; project administration, W.W.; funding acquisition, J.L. All authors have read and agreed to the published version of the manuscript.

Funding: This work was supported by National Natural Science Foundation of China (51907175) and Zhejiang Provincial Natural Science Foundation of China under Grant No. LY21F030002.

Institutional Review Board Statement: Not applicable.

Informed Consent Statement: Not applicable.

Data Availability Statement: Not applicable.

Conflicts of Interest: The authors declare no conflicts of interest. The funders had no role in the design of the study; in the collection, analyses, or interpretation of data; in the writing of the manuscript; or in the decision to publish the results.

\section{Appendix A. Control Parameters}

As elaborated in Section 3.2, the proposed secondary control strategy uses roportionintegration (PI) regulators to restore the bus voltage/frequency. Furthermore, the PI controllers are used for the power flow adjusting. Table A1 shows the control parameters used in the BSHMG project, and most of them are tuned by trial-and-error methods. 
Table A1. Main control parameters in the BSHMG Project.

\begin{tabular}{lll}
\hline Device & Function & Parameter \\
\hline 1\# PFC \& 2\# PFC & DC voltage restoration & $\mathrm{kp}=0.0005, \mathrm{ki}=0.05$ \\
& DC current regulation & $\mathrm{kp}=0.002, \mathrm{ki}=0.2$ \\
& DC voltage droop coefficient & $\mathrm{m}=0.04$ \\
\hline 3\# PFC & AC frequency regulation & $\mathrm{kp}=0.001, \mathrm{ki}=0.1$ \\
& AC voltage regulation & $\mathrm{kp}=0.00005, \mathrm{ki}=0.005$ \\
& AC voltage droop coefficient & $\mathrm{m}=0.00001$ \\
& AC frequency droop coefficient & $\mathrm{n}=0.000005$ \\
& DC current regulation & $\mathrm{kp}=0.002, \mathrm{ki}=0.2$ \\
\hline PET & DC current regulation & $\mathrm{kp}=0.002, \mathrm{ki}=0.2$ \\
\hline Storage & DC voltage restoration & $\mathrm{kp}=0.001, \mathrm{ki}=0.1$ \\
& DC current regulation & $\mathrm{kp}=0.002, \mathrm{ki}=0.2$ \\
\hline
\end{tabular}

\section{References}

1. Huang, J.; Zhang, X.; Mao, T. Multi-time scale frequency regulation of a general resonant DC transformer in hybrid AC/DC microgrid. IEEE Trans. Ind. Electron. 2020. [CrossRef]

2. Yang, P.; Yu, M.; Wu, Q.; Wang, P.; Xia, Y.; Wei, W. Decentralized economic operation control for hybrid AC/DC microgrid. IEEE Trans. Sustain. Energy 2020, 11, 1898-1910. [CrossRef]

3. Zhou, Q.; Shahidehpour, M.; Li, Z.; Che, L.; Alabdulwahab, A.; Abusorrah, A. Compartmentalization strategy for the optimal economic operation of a hybrid AC/DC microgrid. IEEE Trans. Power Syst. 2020, 35, 1294-1304. [CrossRef]

4. Gupta, A.; Doolla, S.; Chatterjee, K. Hybrid AC-DC microgrid: Systematic evaluation of control strategies. IEEE Trans. Smart Grid 2017, 9, 3830-3843. [CrossRef]

5. Najafzadeh, M.; Ahmadiahangar, R.; Husev, O.; Roasto, I.; Jalakas, T.; Blinov, A. Recent contributions, future prospects and limitations of interlinking converter control in hybrid AC/DC microgrids. IEEE Access 2021, 9, 7960-7984. [CrossRef]

6. Zhang, B.; Han, X.; Ren, C.; Zhang, D.; Wang, L.; Song, T. A circulating current suppression method with adaptive virtual impedance for multi-bidirectional power converters under unbalanced conditions. CSEE J. Power Energy Syst. 2020. [CrossRef]

7. Loh, P.C.; Li, D.; Chai, Y.K.; Blaabjerg, F. Autonomous operation of hybrid microgrid with AC and DC subgrids. IEEE Trans. Power Electron. 2013, 28, 2214-2223. [CrossRef]

8. Loh, P.C.; Li, D.; Chai, Y.K.; Blaabjerg, F. Autonomous control of interlinking converter with energy storage in hybrid AC/DC microgrid. IEEE Trans. Ind. Appl. 2013, 49, 1374-1382. [CrossRef]

9. Peyghami, S.; Mokhtari, H.; Blaabjerg, F. Autonomous operation of a hybrid AC/DC microgrid with multiple interlinking converters. IEEE Trans. Smart Grid 2017. [CrossRef]

10. X. Lu, J. M. Guerrero, K. Sun, J. C. Vasquez, R. Teodorescu, and L. Huang, Hierarchical control of parallel AC-DC converter interfaces for hybrid microgrids. IEEE Trans. Smart Grid 2014, 5, 683-692. [CrossRef]

11. Wang, C.; Li, X.; Guo, L.; Li, Y.W. A nonlinear-disturbance-observer-based DC-bus voltage control for a hybrid AC/DC microgrid. IEEE Trans. Power Electron. 2014, 29, 6162-6177. [CrossRef]

12. Liu, X.;Wang, P.; Loh, P.C. A hybrid AC/DC microgrid and its coordination control. IEEE Trans. Smart Grid 2011, 2, 278-286.

13. Wang, J.; Jin, C.; Wang, P. A uniform control strategy for the interlinking converter in hierarchical controlled hybrid AC/DC microgrids. IEEE Trans. Ind. Electron. 2018, 65, 6188-6197. [CrossRef]

14. Yang, P.; Yu, M.; Wu, Q.; Hatziargyriou, N.; Xia, Y.; Wei, W. Decentralized bidirectional voltage supporting control for multi-mode hybrid AC/DC microgrid. IEEE Trans. Smart Grid 2020, 11, 2615-2626. [CrossRef]

15. Wang, L.; Fu, X.; Wong, M.C.W. Operation and control of a hybrid coupled interlinking converter for hybrid AC/lvdc microgrids. IEEE Trans. Ind. Electron. 2020, 68, 7104-7114. [CrossRef]

16. Espina, E.; Cardenas-Dobson, R.; Simpson-Porco, J.W.; Saez, D. and Kazerani, M. A consensus-based secondary control strategy for hybrid AC/DC microgrids with experimental validation. IEEE Trans. Power Electron. 2021, 36, 5971-5984. [CrossRef]

17. Esfahani, M.S.G.; Savaghebi, M. A decentralized control strategy based on v-i droop for enhancing dynamics of autonomous hybrid AC/DC microgrids. IEEE Trans. Power Electron. 2021, 36, 9430-9440.

18. Biglarahmadi, M.; Ketabi, A.; Baghaee, H.R.; Guerrero, J.M. Integrated nonlinear hierarchical control and management of hybrid AC/DC microgrids. IEEE Syst. J. 2021. [CrossRef]

19. Khalid, M. Discussion on "novel supervisory control method for islanded droop-based AC/DC microgrids". IEEE Trans. Power Syst. 2020, 35, 4138-4138. [CrossRef]

20. Li, X.; Guo, L.; Li, Y.; Hong, C.; Zhang, Y.; Guo, Z.; Huang, D.; Wang, C. Flexible interlinking and coordinated power control of multiple DC microgrids clusters. IEEE Trans. Sustain. Energy 2018, 9, 904-915. [CrossRef] 
21. Lou, G.; Gu, W.; Wang, J.; Wang, J.; Gu, B. A unified control scheme based on a disturbance observer for seamless transition operation of inverter-interfaced distributed generation. IEEE Trans. Smart Grid 2018, 9, 5444-5454. [CrossRef]

22. Kleftakis, V.; Lagos, D.; Papadimitriou, C.; Hatziargyriou, N.D. Seamless transition between interconnected and islanded operation of DC microgrids. IEEE Trans. Smart Grid 2017, 10, 248-256. [CrossRef]

23. Nguyen, T.L.; Wang, Y.; Tran, Q.T.; Caire, R.; Xu, Y.; Gavriluta, C. A Distributed Hierarchical Control Framework in Islanded Microgrids and Its Agent-based Design for Cyber-Physical Implementations. IEEE Trans. Ind. Electron. 2020. [CrossRef] 